\title{
Improved xenograft efficiency of esophageal adenocarcinoma cell lines through in vivo selection
}

\author{
ELODIE MELSENS ${ }^{1}$, ELLY DE VLIEGHERE ${ }^{2}$, BENEDICTE DESCAMPS ${ }^{3}$, CHRISTIAN VANHOVE ${ }^{3}$, \\ OLIVIER DE WEVER ${ }^{2}$, WIM CEELEN ${ }^{1}$ and PIET PATTYN ${ }^{1}$ \\ ${ }^{1}$ Laboratory of Experimental Surgery, Department of Surgery, Ghent University Hospital; \\ ${ }^{2}$ Laboratory of Experimental Cancer Research, Department of Radiation Oncology and Experimental Cancer Research, \\ Ghent University; ${ }^{3}$ Infinity (iMinds-IBiTech-MEDISIP), Department of Electronics \\ and Information Systems, Ghent University, Ghent, Belgium
}

Received September 8, 2016; Accepted November 18, 2016

DOI: $10.3892 /$ or.2017.5640

\begin{abstract}
The present study aimed to investigate the orthotopic growth potential of two generally available esophageal adenocarcinoma cell lines, OE33 and OACM5 1.C, and a third in vivo selected subpopulation, OACM5 1.C SC1. One group of mice was subcutaneously injected in the hind legs. Tumor growth was measured with calipers. Another group was injected orthotopically in the distal esophageal wall through median laparotomy. Tumor development was evaluated macroscopically and confirmed microscopically. A subset of mice was evaluated with magnetic resonance imaging (MRI) to follow tumor progression. Additionally, functional cell line characteristics were evaluated in vitro (clonogenic, collagen invasion and sphere formation assays, and protein analysis of cell-cell adhesion and cytoskeletal proteins) to better understand xenograft behavior. OE33 cells were shown to be epithelial-like, whereas OACM5 1.C and OACM5 1.C SC1 were more mesenchymal-like. The three cell lines were non-invasive into native type I collagen gels. In vivo, OE33 cells led to 63.6 and $100 \%$ tumor nodules after orthotopic $(n=12)$ and subcutaneous $(n=8)$ injection, respectively. Adversely, OACM5 1.C cells did not lead to tumor formation after orthotopic injection $(n=6)$ and only $50 \%$ of subcutaneous injections led to tumor nodules $(n=8)$. However, the newly established cell line OACM5 1.C SC1 resulted in 33\% tumor formation when orthotopically injected $(\mathrm{n}=6)$ and in $100 \%$ tumors when injected subcutaneously $(\mathrm{n}=8)$. The higher xenograft rate of OACM5 1.C SC1 $(\mathrm{P}<0.05)$ corresponded with a higher clonogenic potential compared to its parental cell line $(\mathrm{P}<0.0001)$. All models showed local tumor growth without metastasis formation. In conclusion, OACM5 1.C has a poor tumor take rate at an orthotopic
\end{abstract}

Correspondence to: Dr Elodie Melsens, Department of Surgery, Ghent University Hospital, 185 De Pintelaan, Ghent, Belgium E-mail: elodie.melsens@ugent.be

Key words: esophageal adenocarcinoma, orthotopic mouse model, in vivo selection and ectopic site. A subpopulation obtained through in vivo selection, OACM5 1.C SC1, gives a significant higher take rate, ectopically. Furthermore, OE33 establishes orthotopic (and subcutaneous) xenografts in mice. These models can be of interest for future studies, and their slow growth rates are a challenge for therapeutic intervention.

\section{Introduction}

Esophageal cancer is the eighth most common cancer worldwide (1). Despite the latest evolutions in treatment, the overall mortality rate of esophageal cancer patients remains high, with a 5-year survival of only $9.8 \%$ in Europe $(2,3)$. Therefore, the need for the development of new therapies is high and preclinical research plays herein a crucial role.

The majority of preclinical research in esophageal carcinoma has been performed in heterotopic models (subcutaneous xenograft tumors) (4). However, orthotopic tumor models, where tumors are grown at their primary site, are preferred, since they more closely resemble tumor development in patients (5). Furthermore, it has been proven that interaction between the tumor and its microenvironment plays a crucial role during carcinogenesis (6). This tumor microenvironment is considerably different when esophageal tumors are grown subcutaneous (heterotopic), i.e. different blood supplies leading to different metastatic routes.

Various preclinical research in esophageal carcinoma has been performed using orthotopic models. Tumor cells are injected either directly in the esophageal wall, or subcutaneously in donor animals to transplant tumor fragments onto the surgically injured esophageal wall. The surgical procedures to induce orthotopic esophageal tumors are technically challenging due to the location and size of the esophagus in laboratory animals (mostly mice). Five surgical approaches to the esophagus have been described: (i) median laparotomy (7-12), (ii) median laparotomy combined with transgastric approach (13), (iii) subcostal laparotomy (14), (iv) transoral (15) and (v) cervical approach (16). Tumor take varies between 0 and $100 \%$ (mean, $80.06 \%$ ), and seems to depend more on the aggressiveness of the tumor cell line, than on the surgical technique. A total of 9 different 
esophageal squamous cell carcinoma (ESSC) cell lines (81-T, KYSE30, KYSE150, SLMT-1, TE1, TE8, TE4, TE10 and T.Tn) and 3 esophageal adenocarcinoma (EAC) cell lines [(OE19) $(9,11,17,18)$, PT1590 $(10,19)$ and OE33 (9)] have been described for orthotopic use. Since EAC has become the main subtype in patients in the US and Northern and Western Europe (20), the present study focused on EAC. Overall, there is a lack of preclinical orthotopic EAC models. Of the 3 EAC cell lines, previously described, for orthotopic use, OE33 represents locally advanced EAC. This cell line was used by Habibollahi et al for diagnostic properties (9), but only in 5 mice. They described orthotopic OE33 tumors of 2-3 mm in diameter at 4 weeks after injection. OE19 and PT1590, in contrast, are representative cell lines for aggressive metastatic EAC. Moreover, OE19 overexpresses Her2, which is found in only a minority of EAC patients [17-32\% of gastroesophageal junction (GEJ) tumors (21)].

The aim of the present study was to establish an orthotopic EAC model in the mouse based on two generally available human EAC cell lines, OE33 and OACM5 1.C. In vivo tumor take and growth were evaluated (orthotopic as well as subcutaneous) and in vitro cell line characterization was performed.

\section{Materials and methods}

\section{In vitro}

Cell lines. The human EAC cell lines OE33 and OACM5 1.C were obtained from Dr W. Dinjens (Department of Pathology, Erasmus MC, Rotterdam, The Netherlands) and are available at the European Collection of Authenticated Cell Cultures (ECACC) (nos. 96070808 and 11012006, respectively). MDA-MB-231 GFP Luc, human mammary carcinoma cell lines (ATCC, HTB-26) and HCT8/E11, human colon adenocarcinoma cell line (ATCC no. CCL-244), were controls for the in vitro experiments. OE33, HCT-8/E11 and MDA-MB-231 GFP Luc were cultured at $37^{\circ} \mathrm{C}$ in a $10 \% \mathrm{CO}_{2}$ humidified atmosphere in Dulbecco's modified Eagle's medium (DMEM) (Life Technologies, Ghent, Belgium), supplemented with 10\% fetal bovine serum (FBS), penicillin-streptomycin and fungizone. Doxycycline $(50 \mu \mathrm{g} / 100 \mathrm{ml}$ medium) was added to the medium of the MDA-MB-231 GFP Luc cell line to express GFP. OACM5 1.C and the in vivo selected cell line OACM5 1.C $\mathrm{SC} 1$ (described below) were cultured at $37^{\circ} \mathrm{C}$ in $5 \% \mathrm{CO}_{2}$ humidified atmosphere in RPMI-1640 medium supplemented with GlutaMAX ${ }^{\mathrm{TM}}$-I (both from Life Technologies), 10\% FBS, penicillin-streptomycin and fungizone. EAC cell lines and the in vivo selected cell line OACM5 1.C SC1 were authenticated by STR DNA profiling. Microscopic images were captured using a phase contrast microscope (Leica DMI3000B; Leica, Diegem, Belgium).

Sphere formation assay. One million single cells were diluted in $6 \mathrm{ml}$ culture medium in an Erlenmeyer flask $(50 \mathrm{ml})$. They were incubated for $72 \mathrm{~h}$ on a Gyrotory shaker at $37^{\circ} \mathrm{C}$ and $70 \mathrm{rpm}$ in 5 or $10 \% \mathrm{CO}_{2}$. Aggregation was analyzed with a phase contrast microscope and was scored on at least 50 aggregates. They were scored as compacted (individual cells not visible) or loose (individual cells still visible) $(n=2)$. HCT8/E11 and MDA-MB-231 GFP Luc cells were used as a control for a respectively compacted and loose sphere formation.
Collagen invasion assay. The assay was performed as described in a previous study (22). Briefly, $1 \times 10^{5}$ cells were seeded as a single-cell suspension on a $0.1 \%$ type I collagen gel (Santa Cruz Biotechnology, Inc., Santa Cruz, CA, USA). After $24 \mathrm{~h}$ of incubation at $37^{\circ} \mathrm{C}$ and 5 or $10 \% \mathrm{CO}_{2}$, invasiveness was scored $(n=2 \times 2)$ and expressed as a mean. HCT8/E11 and MDA-MB-231 GFP Luc cells were used as a control for a respectively high and low invasive cell line.

Colony formation assay. Single cells $(1,000)$ were seeded in T75 falcons ( $15 \mathrm{ml}$ culture medium) and cultured for 14 days at $37^{\circ} \mathrm{C}$. Colonies were stained with $0.5 \%$ crystal violet, scanned and counted using ImageJ software (NIH, Bethesda, MA, USA). Results are expressed as the mean percentage of colonies formed from 1,000 cells [colony formation index (CFI)] ( $n=2 \times 5)$. HCT8/E11 and MDA-MB-231 GFP Luc cells were used as a control for a respectively positive and negative colony formation cell line.

Western blotting. Cells were lysed and sonicated for $10 \mathrm{sec}$ on ice. Lysates were diluted to a protein concentration of $1 \mu \mathrm{g} / \mu \mathrm{l}$ and boiled for $5 \mathrm{~min}$ at $95^{\circ} \mathrm{C}$. Equal amounts of proteins were separated on 8 and 10\% gels and transferred to nitrocellulose membranes. Membranes were blocked [phosphate-buffered saline (PBS), 5\% non-fat milk, 0.5\% Tween] and immunostained with primary antibodies: E-cadherin M106 (Takara, The Netherlands), P-cadherin 610228 (BD Biosciences, Erembodegem, Belgium), vimentin V6389, $\alpha$-catenin C2081, $\beta$-catenin C2206 and cytokeratin C2931, recognizing subtype $(4,5,6,8,10,13$ and 18) (Sigma-Aldrich, St. Louis, MO, USA). Then, the secondary antibodies were applied, either ECL ${ }^{\mathrm{TM}}$ anti-mouse IgG or $\mathrm{ECL}^{\mathrm{TM}}$ anti-rabbit IgG (GE Healthcare UK Ltd., Buckinghamshire, UK).Immunodetection was performed with Pierce ECL Western Blotting Substrate (Thermo Scientific, Rockford, IL, USA) and imaged with ProXima 2850 (Isogen Life Science, De Meern, The Netherlands). HCT8/E11 was used as positive control for E-cadherin, P-cadherin and cytokeratin. MDA-MB-231 GFP Luc cells were used as a positive control for vimentin. Both cell lines were positive controls for $\alpha$-catenin and $\beta$-catenin.

\section{In vivo}

Animals. Animal experiments were approved by the Animal Ethics Committee of Ghent University, Belgium (ECD 14/82). Athymic mice (Foxn $1^{n u}$ male) were obtained from Envigo (The Netherlands), and were kept under environmentally controlled conditions (12-h normal light/dark cycle, $20-23^{\circ} \mathrm{C}$ and $50 \%$ relative humidity) with food and water ad libitum. At 8 weeks of age, tumor cells were implanted (subcutaneous or orthotopic) under general anesthesia (Isoflurane, Abbott, Belgium). At the end of the experiments, or when humane endpoints were reached, mice were euthanized by cervical dislocation.

Subcutaneous tumor model. Subcutaneous tumors were grown to evaluate overall growth behavior of the cell lines in mice and to provide tumors for in vivo selection of cancer cells. Under general anesthesia, tumor cells suspended in $100 \mu \mathrm{l}$ of Matrigel/injection site were injected SC in both hind legs. Tumor nodules were measured biweekly with calipers and 

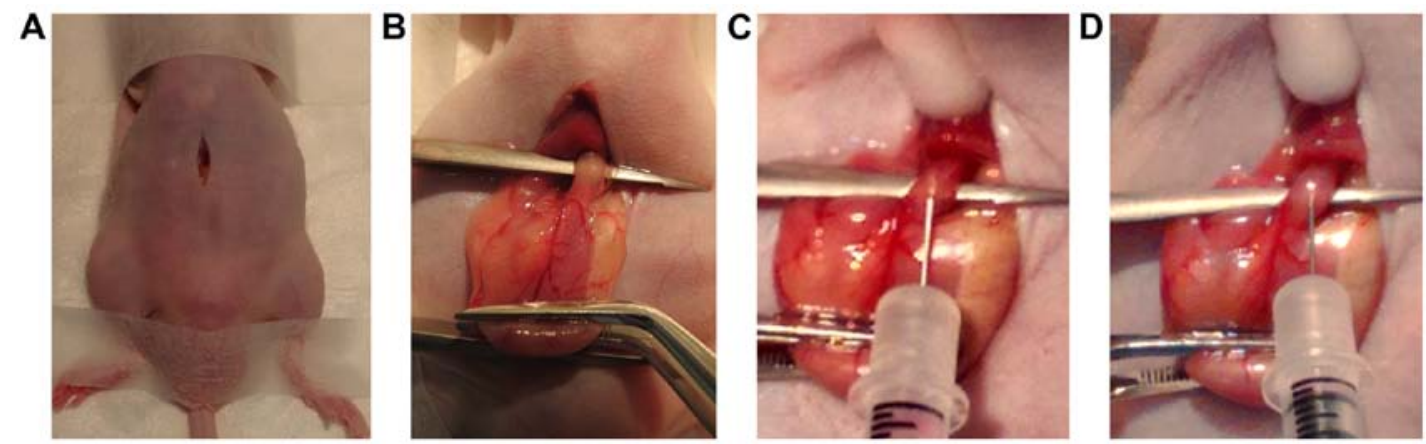

Figure 1. Surgical technique of the orthotopic injection of tumor cells. (A) Upper abdominal median laparotomy in a mouse under general inhalation anesthesia, positioned using tape. (B) The stomach is lifted extra-corporal with a forceps. Another forceps (micro-instrument) is positioned underneath the esophagus to improve the access. (C) Insertion of a 30-G needle in the distal esophageal wall. (D) Injection of tumor cells in Matrigel resulting in a bleb in situ.

volumes were calculated according to the following formula: $\mathrm{V}=(\text { length } \mathrm{x} \text { width) })^{3 / 2} \mathrm{x} \pi / 6$.

Orthotopic tumor model. Mice were supine positioned on a heating pad. Under general anesthesia and analgesia (ketoprofen, $5 \mathrm{mg} / \mathrm{kg}$, SC) a vertical skin incision of $10 \mathrm{~mm}$ was medially performed in the upper abdomen. Abdominal muscles were split and the peritoneum was opened through sharp dissection (Fig. 1A). The liver was gently elevated with a moist Q-tip to give access to the abdominal esophagus. The stomach was lifted extra-corporeally by traction on the greater curvature with a forceps. A micro-forceps was positioned underneath the distal esophagus to lift it (Fig. 1B). While the esophagus was stretched by gentle tension on the stomach by an assistant, a 30-gauge needle was inserted in the distal part of the esophageal wall and tunneled approximally for $\sim 3 \mathrm{~mm}$ (Fig. 1C). Tumor cells, suspended in $20 \mu \mathrm{l}$ Matrigel/animal were injected slowly, resulting in local bulging (Fig. 1D). At body temperature, Matrigel solidifies within seconds, minimalizing the risk of intra-abdominal spilling of tumor cells. The stomach was cautiously repositioned and the abdominal wall and skin were closed with a running PDS 6-0 suture. Hartmann solution $(500 \mu \mathrm{l})$ was administered SC to prevent dehydration. Animals were followed up daily, and weighed 2 times/week.

Subcutaneous $\left(\mathrm{TT}_{\mathrm{SC}}\right)$ and orthotopic tumor take $\left(\mathrm{TT}_{\text {orth }}\right)$ were defined as the percentage of macroscopic tumor nodules (confirmed on histology) over the total number of injections. At 7 weeks, mice were euthanized and tumors were excised for histopathology.

Magnetic resonance imaging. A subpopulation of mice with orthotopic tumors (OE33 tumor nodules, n=5) were evaluated by magnetic resonance imaging (MRI) at 1, 2, 3, 5, 8 and 12 weeks after tumor injection to follow tumor progression. MR images were acquired on a 7T system (Bruker PharmaScan 70/16, Ettlingen, Germany) with a mouse body volume coil. Mice were anesthetized with isoflurane $(5 \%$ induction, $1.5 \%$ maintenance, $0.3 \mathrm{l} / \mathrm{min}$ ) and warmed with a water-based heating blanket. Respiration was monitored using a respiration pad underneath the mouse. Anatomical information was obtained with a T2-weighted sequence (TurboRARE) with the following parameters: TR, 3,661 and TE, $37.1 \mathrm{msec}$, $109 \mu \mathrm{m}$ in-plane resolution, 30 contiguous transverse slices of $600 \mu \mathrm{m}$, and acquisition time 9'1". Mice were euthanized 15 weeks after tumor induction.

In vivo selection of cancer cells. To obtain subcultures of cell lines that grow well in mice, tumors (SC and orthotopic) were excised under sterile conditions and divided into small pieces. Tumor fragments were dissociated (gentleMACS Dissociator; Miltenyi Biotec GmbH, Bergisch Gladbach, Germany) along with a collagenase $1 \mathrm{mg} / \mathrm{ml}$ (Sigma-Aldrich) in $\mathrm{PBS}^{\mathrm{D}+}$ mixture to disrupt tissue structures. The suspension was filtered through a cell strainer $(70 \mu \mathrm{m})$, and centrifuged. Cells were seeded in $\mathrm{T} 75$ falcons and incubated. After $24 \mathrm{~h}$, non-adherent cells were cleared and replaced by fresh culture medium.

Tumor samples and histology. Tumors were excised, fixed with $4 \%$ formaldehyde, processed and embedded in paraffin. Tumor sections of $5 \mu \mathrm{m}$ were cut with a microtome (Microm HM355S; Thermo Scientific). Hematoxylin and eosin (H\&E) and Ki67 stainings [ready-to-use DAKO EnVision ${ }^{\mathrm{TM}}+$ System-HRP kit (K4011)] were performed according to the standard protocols. Slides were scanned on magnifications of $\mathrm{x} 100$ and $\mathrm{x} 200$, and proliferation indices were determined by an overall visual scoring system. Tumors were categorized as lowly, moderately or highly proliferative. Microscopic images were captured with a light microscope (ColorView I, BX43F; Olympus, Tokyo, Japan).

Statistical methods. Statistical analysis was performed using GraphPad Prism 6 (GraphPad Software, Inc., La Jolla, CA, USA). Mann-Whitney test was used to compare the in vitro results of the parental and in vivo selected cell line. Fisher's exact test was used to compare tumor take rates. Results are summarized as mean with standard deviation (SD), and were considered statistically significant when the probability of a type I error was $\leq 0.05$.

\section{Results}

Cell characterization of OE33. OE33 cells had an epithelial morphology, characterized by adherent cells, cell-cell contacts and a typical formation of islands (Fig. 2A, upper panel). These cell-cell contacts resulted in the ability to form compact spheres under Gyrotory shaking (Fig. 2A, middle panel). On 


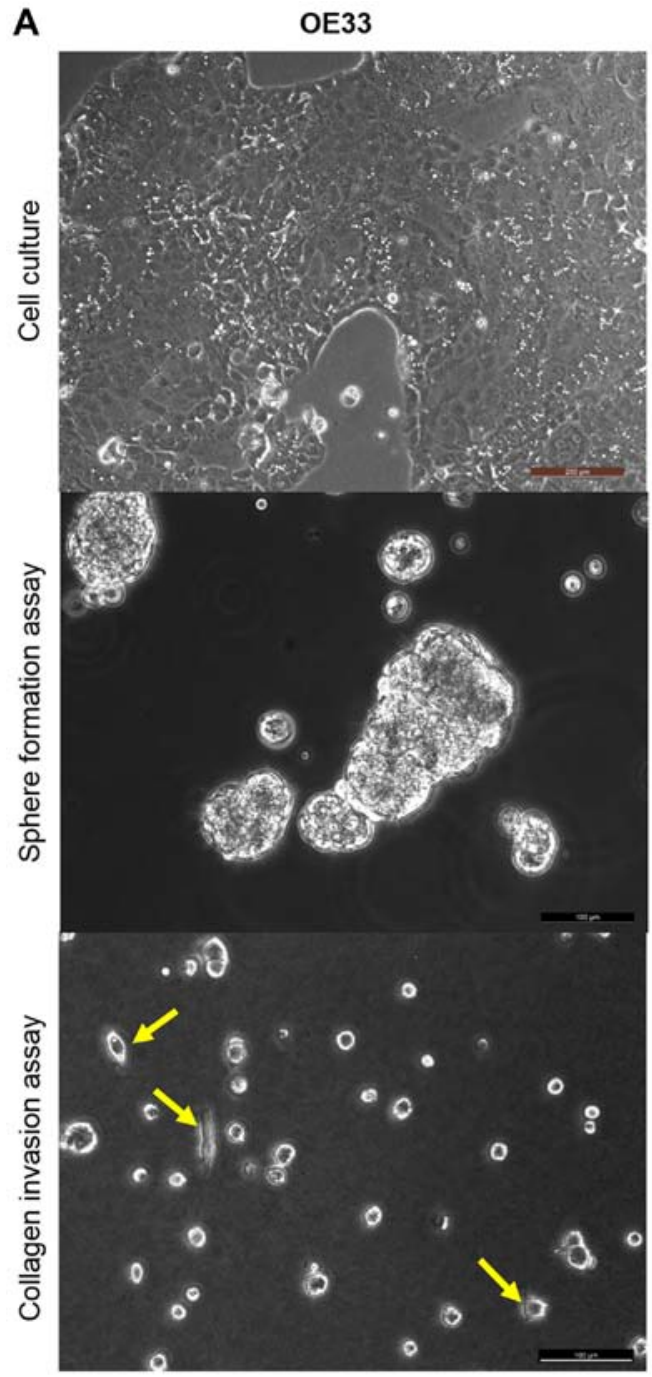

B
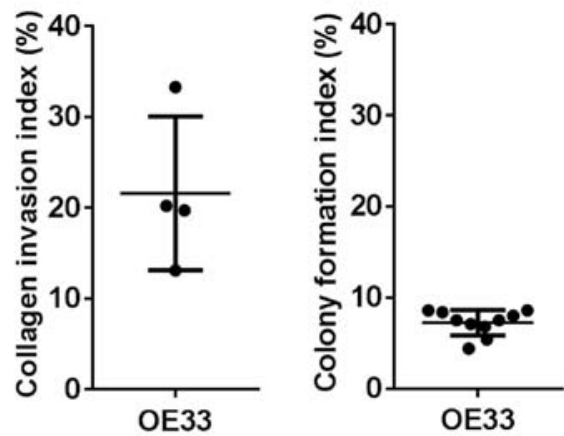

C

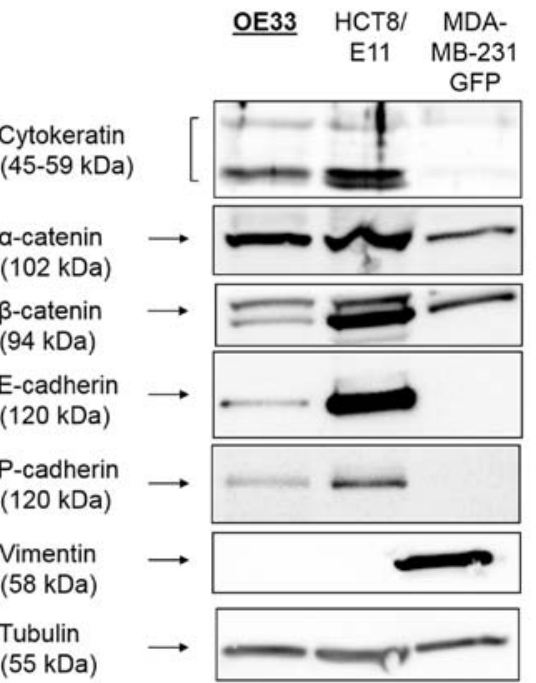

Figure 2. In vitro characteristics of OE33 cells. (A) Upper panel: cells in culture; phase contrast image (scale bar, $200 \mu \mathrm{m}$ ). Middle panel: sphere formation assay $72 \mathrm{~h}$ after initiation; phase contrast image (scale bar, $100 \mu \mathrm{m}$ ). Lower panel: collagen type I invasion assay $24 \mathrm{~h}$ after seeding; phase contrast image (scale bar, $100 \mu \mathrm{m}$ ). Yellow arrows show invasive cells in collagen type I gel. (B) Left graph: collagen invasion index (\%). Right graph: colony formation index (\%). Single values, mean, standard deviation. (C) Western blotting of OE33 cells compared to HCT8/E11 and MDA-MB-231 GFP Luc cells.

type I collagen gels, $21.6 \%$ [95\% confidence interval (CI), 8.12 and $35.04 \%)]$ of the OE33 cells showed cellular extensions invading the matrix (Fig. 2A, lower panel; and B, left). When seeded at a low density on tissue culture substrate, only a limited number of these cells were able to form a colony [mean CFI, $7.23 \%$; 95\% CI, 6.24 and 8.23\%)] (Fig. 2B, right). Additionally, western blotting was performed (Fig. 2C). OE33 cells expressed cytokeratin, an intermediate filament supporting the epithelial origin of the cancer cell line. Furthermore, the cells showed expression of $\alpha$-catenin, $\beta$-catenin, E-cadherin and P-cadherin, proteins important for cell-cell adhesion and tissue organization. They did not express vimentin, a major cytoskeletal component in mesenchymal cells.

Tumor development with OE33. Four mice were subcutaneously injected bilaterally with OE33 cells (Table I). These all resulted in similar small tumor nodules, but volumes seemed to decrease, progressively (Fig. 3A). Histologically, nodules consisted of well-differentiated tumor cells organized in islands and surrounded by infiltrating stromal cell connective tissue (Fig. 3B and C). They were not invasive into surrounding tissues and Ki67 indices were low to moderate (Fig. 3D). Two nodules were used for in vivo selection and were confirmed to contain tumor cells through that means.

Twelve mice were orthotopically injected with OE33 cells (Table I). Seven animals developed tumor nodules at the distal site of the esophagus without evidence of metastasis (liver, diaphragm, peritoneum and omentum were free of lesions) (Fig. 4A). Tumors were located at the submucosal space and were not invasive into surrounding tissue (Fig. 4B and D). They were well differentiated and had a low proliferation index (Fig. 4C). Three nodules were used for in vivo selection and were confirmed to contain tumor cells through that means.

MRI scans were performed in a subset of mice $(n=5)$ to follow tumor development (Fig. 5A). At the initial MRI scan 1 week post-tumor induction, all of them showed a clear tumor-like nodule at the distal site of the esophagus. During follow-up, volumes remained the same and at the end 4 out of 5 animals showed a tumor-like nodule on MRI. These were confirmed to contain tumor cells microscopically (Fig. 5B-D). 


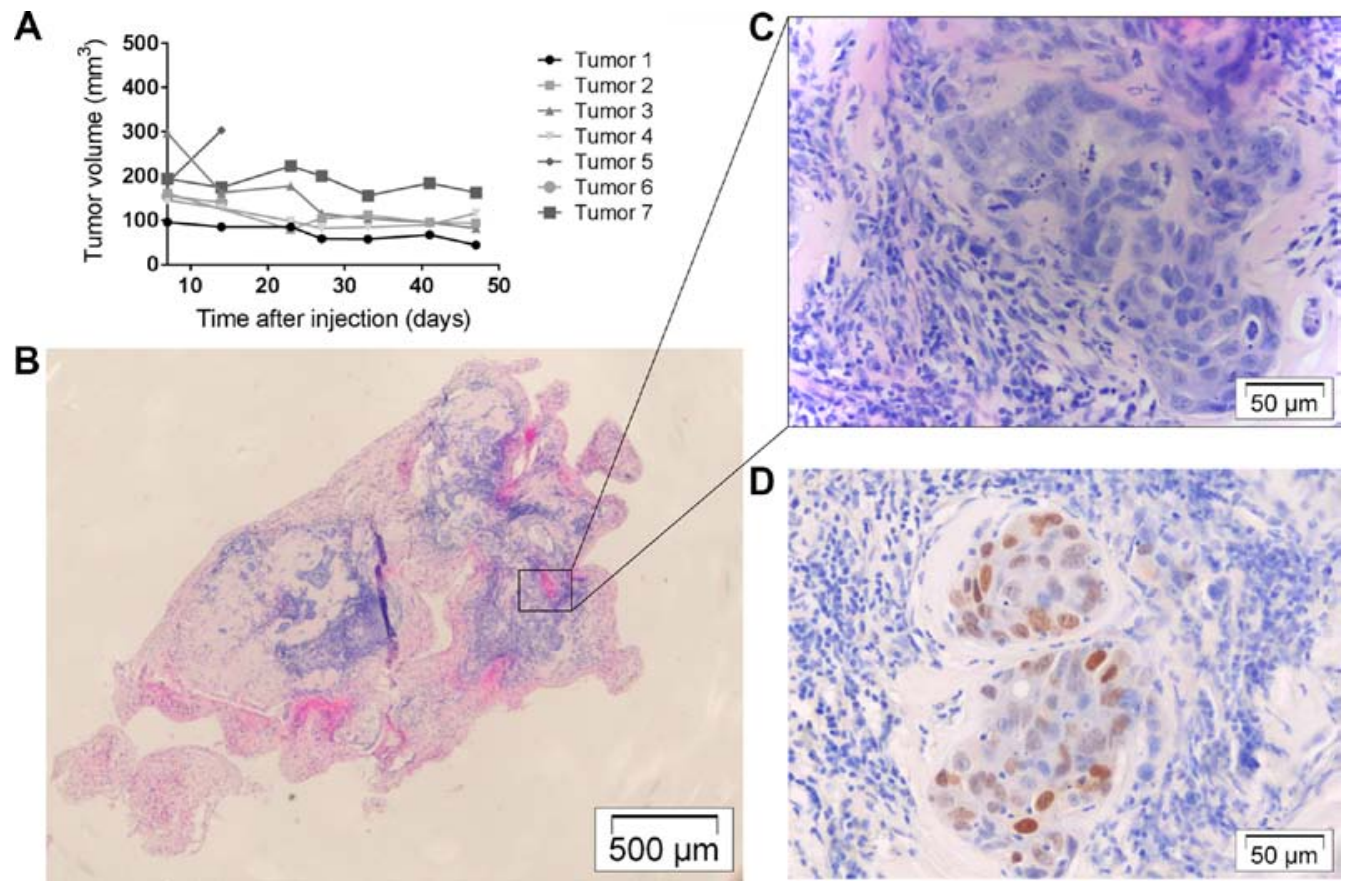

Figure 3. Subcutaneous (SC) xenograft OE33 tumors. (A) Tumor volumes $\left(\mathrm{mm}^{3}\right)$ of $7 \mathrm{SC}$ tumors determined at different times after injection of tumor cells. (B and C) Hematoxylin and eosin (H\&E) staining of SC tumor at different magnifications. (D) Ki67 staining of the adjacent tumor slide.
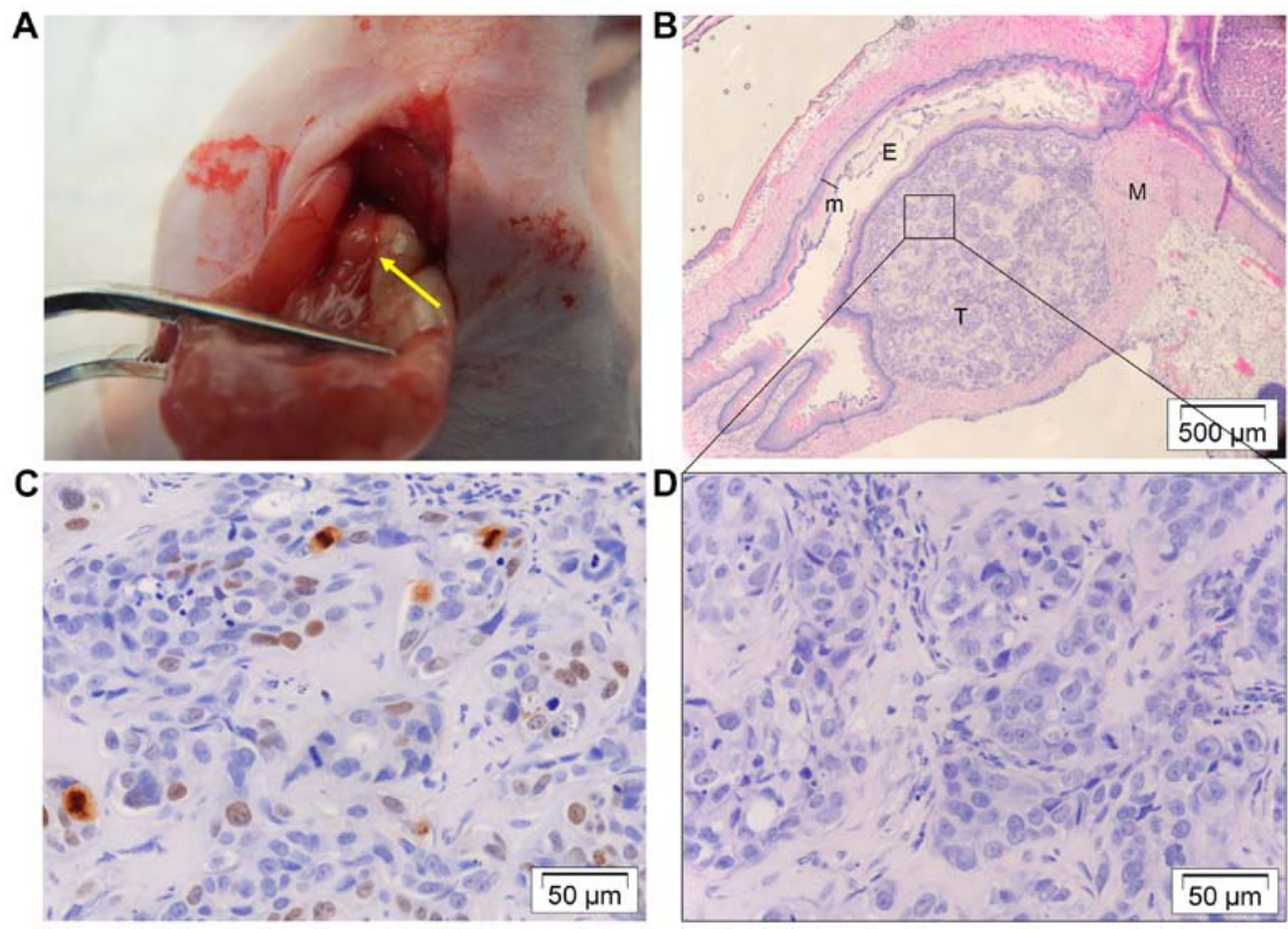

Figure 4. Orthotopic xenograft OE33 tumor. (A) Macroscopic tumor nodule at the distal site of the esophagus (yellow arrow). The stomach is pulled downwards with a forceps. (B and D) Hematoxylin and eosin (H\&E) staining of a tumor nodule. E, esophageal lumen; T, tumor nodule; M, muscle layers of the esophageal wall; $\mathrm{m}$, esophageal mucosa. The nodule is situated in the submucosal space and does not invade the mucosa. In the right upper corner, the transition to the stomach is situated. (C) Ki67 staining of the adjacent tumor slide.

Cell characterization of OACM5 1.C. OACM5 1.C cells had two morphological subtypes: a majority of multicellular floating cell clusters, and some adherent cells with a fibroblastlike appearance, growing as single cells (Fig. 6A, upper panel). These did not form cell-cell contacts, and only very few cells were adherent to plastic. OACM5 1.C cells were not able to form compact spheres under Gyrotory shaking, but formed loose cell clusters with recognition of individual cells (Fig. 6A, middle panel). Furthermore, they were non-invasive into collagen gels [mean 1.38\%, 95\% CI, -0.30 and 2.47\%)] (Fig. 6A 
Table I. Summary of in vivo experiments.

\begin{tabular}{|c|c|c|c|c|c|c|c|c|}
\hline & \multicolumn{4}{|c|}{ OE33 } & \multicolumn{2}{|c|}{ OACM5 1.C } & \multicolumn{2}{|c|}{ OACM5 1.C SC1 } \\
\hline & \multicolumn{2}{|c|}{$\mathrm{SC}$} & \multicolumn{2}{|c|}{ Orthotopic } & \multirow{2}{*}{$\frac{\mathrm{SC}}{}$} & \multirow{2}{*}{$\frac{\text { Orthotopic }}{}$} & \multirow{2}{*}{$\frac{\mathrm{SC}}{}$} & \multirow{2}{*}{$\frac{\text { Orthotopic }}{}$} \\
\hline Injected tumor cells $\left(\mathrm{x} 10^{6}\right)$ & 1 & 5 & 0.5 & 1 & & & & \\
\hline Number of tumor cell implantations & $\mathrm{n}=2$ & $\mathrm{n}=5$ & $\mathrm{n}=5$ & $\mathrm{n}=7$ & $\mathrm{n}=8$ & $\mathrm{n}=6$ & $\mathrm{n}=10$ & $\mathrm{n}=6$ \\
\hline Macroscopic tumor nodule & $2 / 2$ & $5 / 5$ & $3 / 4^{\mathrm{a}}$ & $4 / 7$ & $4 / 8$ & $0 / 4^{b}$ & $10 / 10$ & $2 / 6$ \\
\hline Microscopic tumor cells & $2 / 2$ & $5 / 5$ & $3 / 4$ & $4 / 7$ & $7 / 8$ & $0 / 4$ & $10 / 10$ & $3 / 6$ \\
\hline Tumor take (TT) (\%) & \multicolumn{2}{|c|}{100} & \multicolumn{2}{|c|}{63.6} & 50 & 0 & 100 & 33.3 \\
\hline
\end{tabular}

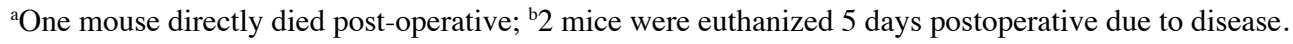

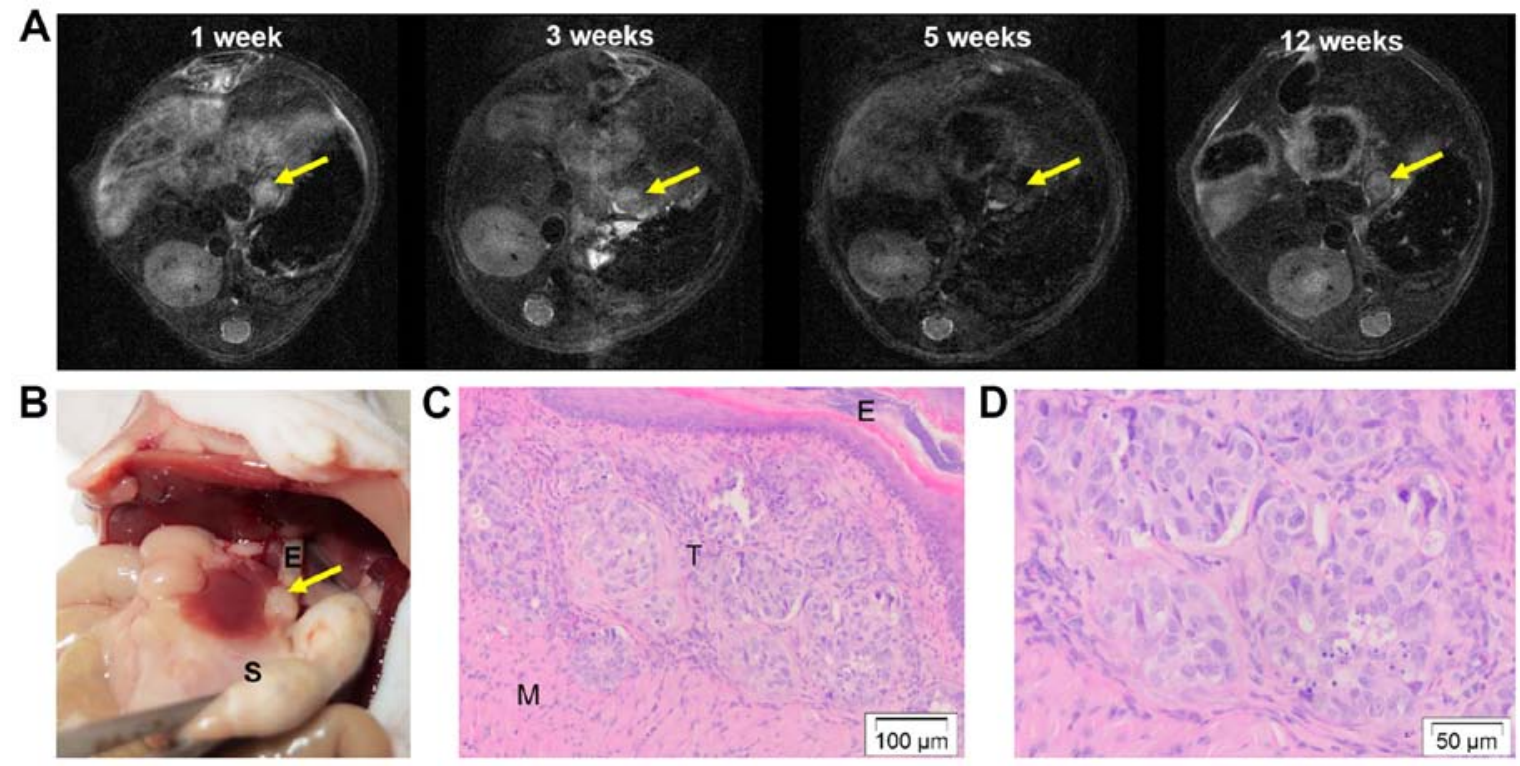

Figure 5. MRI images of orthotopic OE33 esophageal tumor. (A) Transverse MRI images at different time points (in weeks) after tumor induction. Yellow arrow, tumor nodule. (B) Macroscopic tumor (yellow arrow) at distal esophagus; E, esophagus; S, stomach. (C and D) Hematoxylin and eosin (H\&E) staining of tumor. T, tumor nodule; E, esophagus; M, muscle layer of esophageal wall.

lower panel, and B, upper graph), and were not clonogenic [CFI $=0.10 \%, 95 \%$ CI, -0.001 and $0.201 \%$ ) ] (Fig. 6B, lower graph). OACM5 1.C cells expressed cytokeratin as determined by western blotting supporting the epithelial origin of the cancer cell line. They expressed $\beta$-catenin and poorly expressed $\alpha$-catenin, but lacked expression of E-cadherin to consolidate cell-cell contacts. OACM5 1.C expressed vimentin representing the mesenchymal characteristics of the cell line (Fig. 6C).

Tumor development with OACM5 1.C. Four mice were subcutaneously injected bilaterally with OACM5 1.C cells (Table I). Four out of 8 injections resulted in macroscopic tumor nodules. One nodule had an exponential growth curve, while the others remained stable (Fig. 7A). Histology showed nodules packed with tumor cells with little infiltrating stromal cells. They were not invasive into surrounding tissues and Ki67 staining was overall low to moderate (Fig. 7B-D). Injection sites that did not develop macroscopic nodules (4/8) resulted in palpable fibrous remnants in which some loose tumor cell islands could be identified on histology. One nodule was used for in vivo selection, and was confirmed to contain tumor cells through that means. An additional 6 mice were orthotopically injected with OACM5 1.C cells (Table I). Of 4 mice evaluable, no tumor nodules, metastasis or involved lymph nodes were macroscopically visible and histology was negative for tumor cells.

Establishment of new in vivo selected cell line OACM5 1.C SC1. OACM5 1.C cells harvested from a SC tumor nodule, were stable through different in vitro passages and were re-injected into mice according to the above protocols. Five mice were subcutaneously injected bilaterally with OACM5 1.C SC1 cells, resulting in 10 macroscopically visible tumors (Table I). Five out of 10 were fast growing (Fig. 8A). Histology showed the presence of tumor cells in all nodules (Fig. 8B and C) and Ki67 staining was low to moderate (Fig. 8D). An additional 6 mice were orthotopically injected with OACM5 1.C SC1 cells, leading to 2 small macroscopic tumor nodules (Table I). 


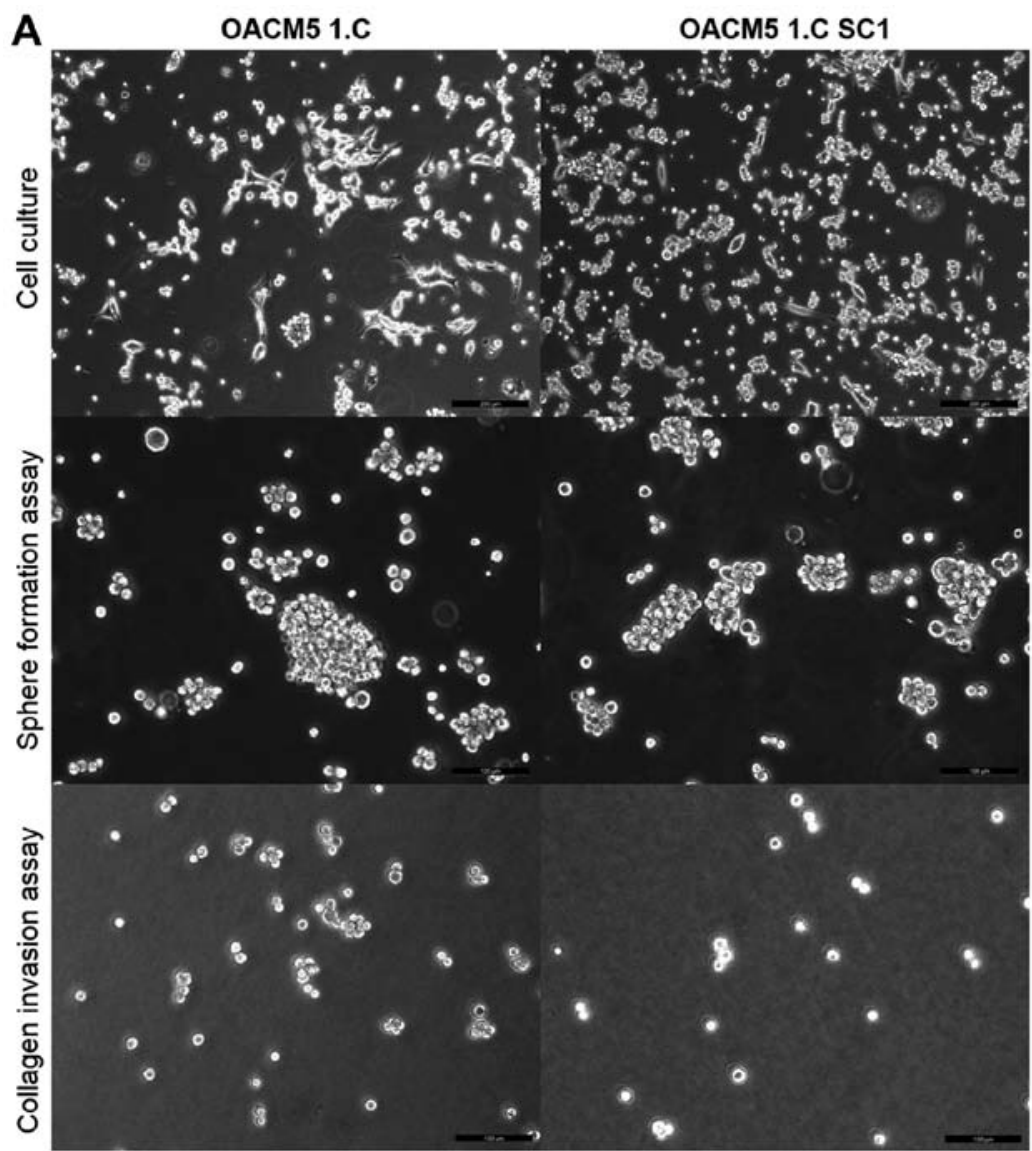

B
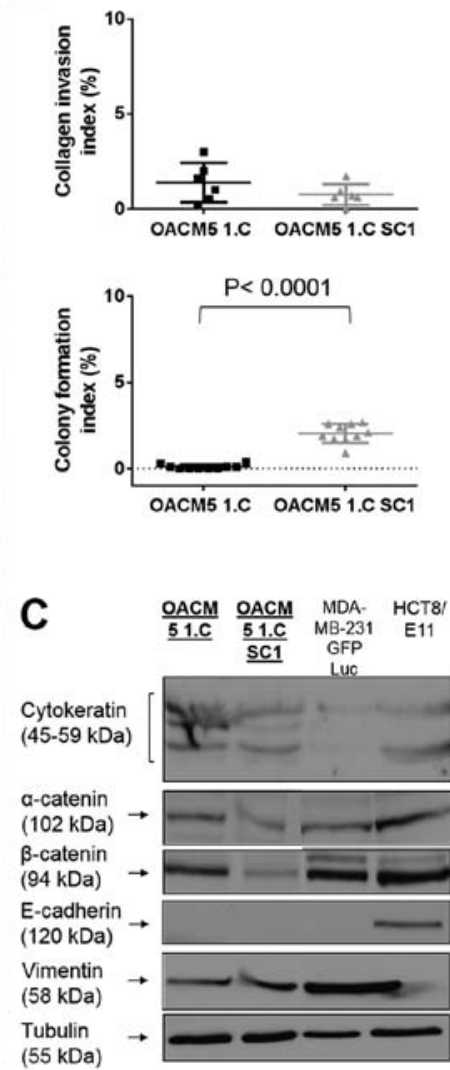

Figure 6. In vitro characteristics of OACM5 1.C and OACM5 1.C SC1 cells. (A) Upper panel: Cell lines in culture; phase contrast image (scale bar, $200 \mu \mathrm{m}$ ). Middle panel: sphere formation assay $72 \mathrm{~h}$ after initiation; phase contrast image (scale bar, $100 \mu \mathrm{m}$ ). Lower panel: collagen type I invasion assay $24 \mathrm{~h}$ after seeding; phase contrast image (scale bar, $100 \mu \mathrm{m}$ ). (B) Upper graph,:collagen invasion index (\%); single values, mean, standard deviation; P=0.368. Lower graph: colony formation index (\%); single values, mean, standard deviation; P<0.0001. (C) Western blotting of OACM5 1.C and OACM5 1.C SC1 cells compared to MDA-MB-231 GFP Luc and HCT8/E11 cells .

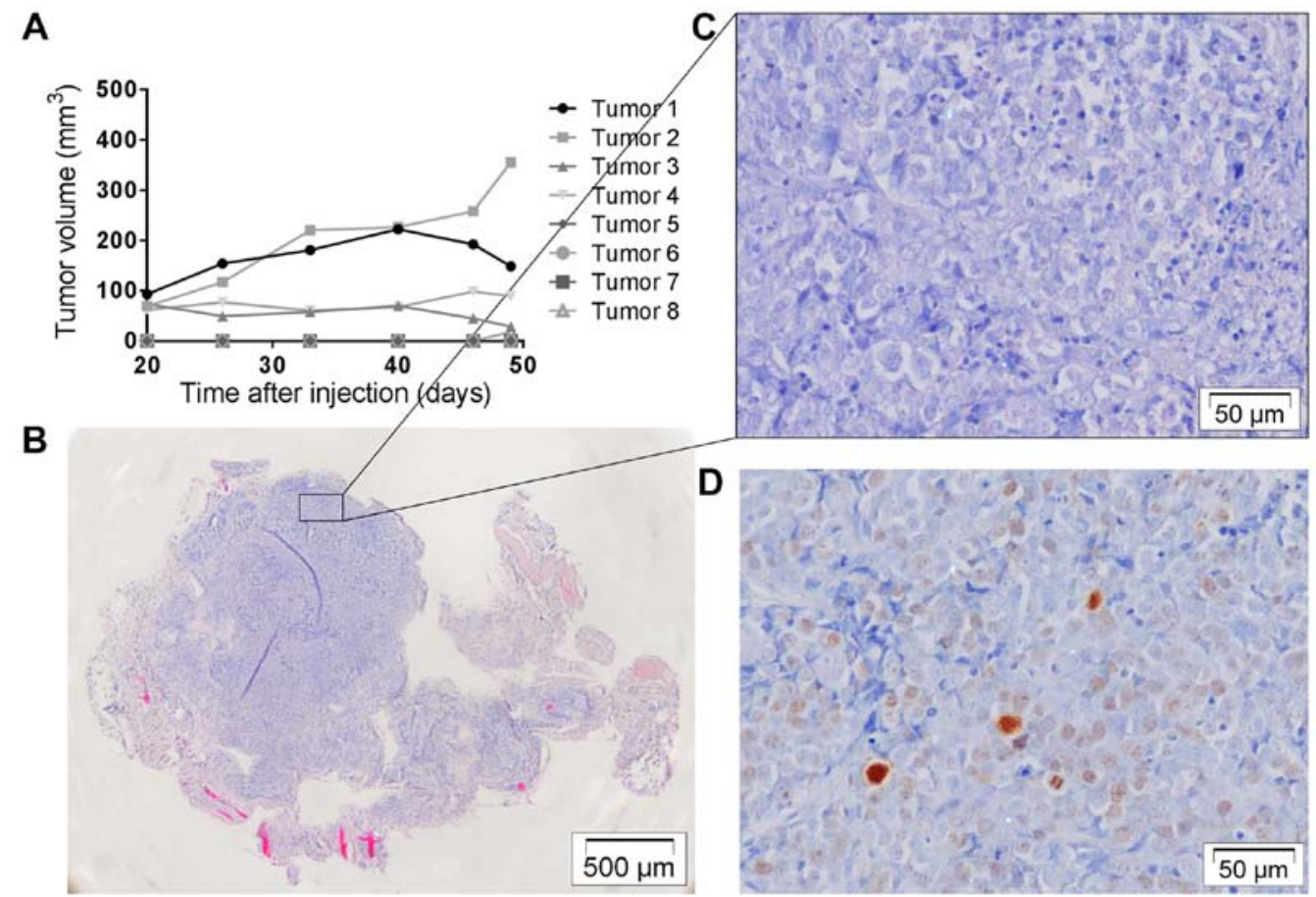

Figure 7. Subcutaneous (SC) xenograft OACM5 1.C tumors. (A) Tumor volumes $\left(\mathrm{mm}^{3}\right)$ of $8 \mathrm{SC}$ tumors determined at different times after injection of tumor cells. Injections (4 out of 8) did not develop tumor nodules. (B and C) Hematoxylin and eosin (H\&E) staining of SC tumor at different magnifications. (D) Ki67 staining of the adjacent tumor slide. 


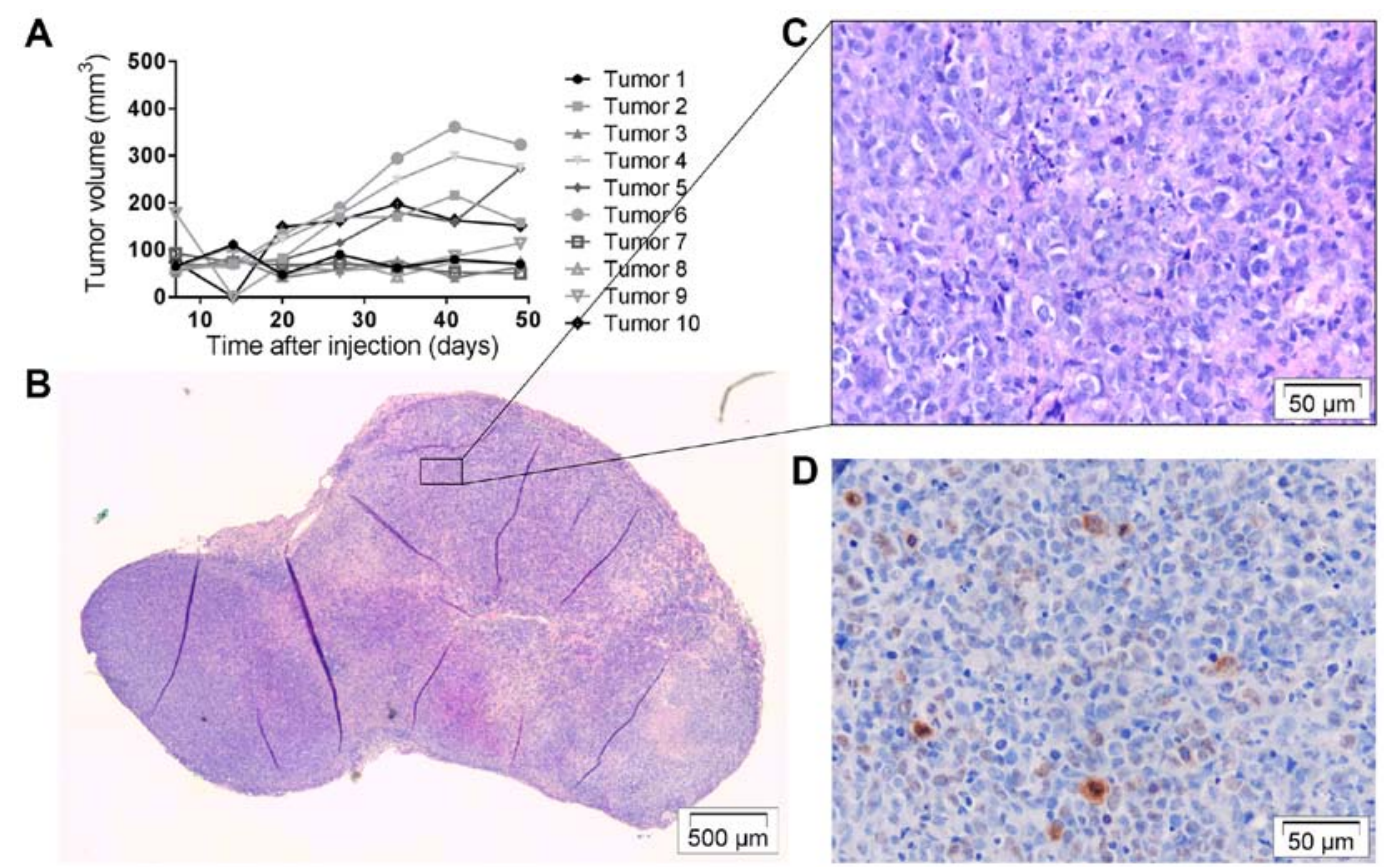

Figure 8. Subcutaneous (SC) xenograft OACM5 1.C SC1 tumor. (A) Tumor volumes $\left(\mathrm{mm}^{3}\right)$ of $10 \mathrm{SC}$ tumors determined at different times after injection of tumor cells. (B) Hematoxylin and eosin (H\&E) staining of SC tumor and at (C) higher magnification; packed with tumor cells. (D) Ki67 staining of the adjacent tumor slide.
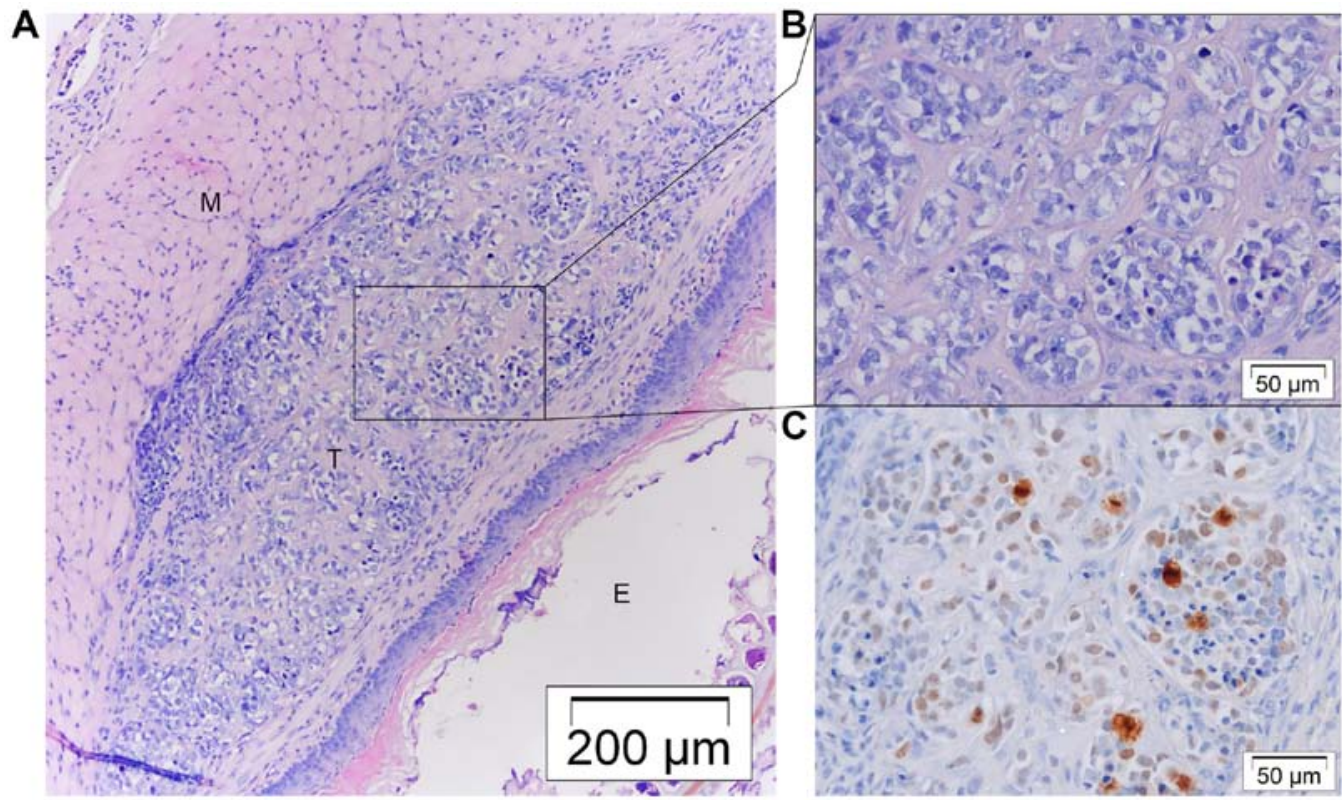

Figure 9. Orthotopic xenograft OACM5 1.C SC1 tumor. (A and B) Hematoxylin and eosin (H\&E) staining of orthotopic OACM5 1.C SC1 tumor nodule, situated at the submucosal space. E, esophageal lumen; T, tumor nodule; M, muscle layers of the esophageal wall. (C) Ki67 staining of the adjacent tumor slide.

No metastasis was observed. Histology confirmed the presence of tumor cells, and nodules did not invade surrounding tissues (Fig. 9A-C). In vivo selection of OE33 cells was not successful ( $n=5)$. Tumor cells were microscopically present, but did not survive different in vitro passages.

Comparison of OACM5 1.C and OACM5 1.C SC1. Both cell lines had the same morphological appearance in vitro (Fig. 6A, upper panel) and in vivo (Figs. 7 and 8).
Furthermore, they had the same cell line characteristics concerning sphere formation and collagen invasion (Fig. 6A and B). Moreover, cell-cell adhesion and cytoskeletal protein expression were similar (Fig. 6C). However, the in vivo selected cell line had higher subcutaneous tumor take rates when compared with the parental cell line $\left[\mathrm{TT}_{\mathrm{sc}}=100\right.$ vs. $50 \%(\mathrm{P}<0.023)$ (Fig. 10)]. This may be related to the significant higher clonogenicity $(\mathrm{P}<0.0001)$ of the in vivo selected cell line compared to the parental cell line in vitro. 


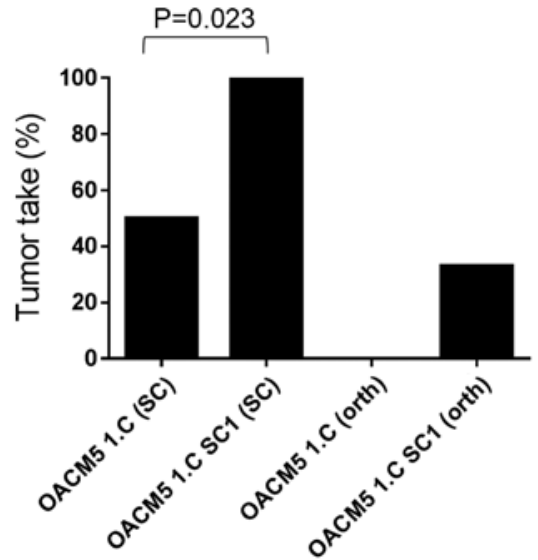

Figure 10. Tumor take of OACM5 1.C and OACM5 1.C SC1 cells. Subcutaneous (SC) and orthotopic tumor take were compared between the two cell lines. Development of tumors was expressed as a percentage of the total amount of implanted tumors: OACM5 1.C (SC) $(\mathrm{n}=4 / 8)$ vs. OACM5 1.C $\mathrm{SC} 1$ (SC) $(\mathrm{n}=10 / 10)$; OACM5 1.C (orth) $(\mathrm{n}=0 / 6)$ vs. OACM5 1.C SC1 (orth) $(\mathrm{n}=2 / 6)$. Subcutaneous tumor take was significantly increase with the in vivo selected cell line (OACM5 1.C SC1) compared to the parental cell line (OACM5 1.C) $(\mathrm{P}<0.023)$. The observed increase in orthotopic tumor take was not statistically significant $(\mathrm{P}=0.4667)$.

\section{Discussion}

The present study investigated the orthotopic growth potential of two generally available EAC cell lines, OE33 and OACM5 1.C, and a third cell line obtained through in vivo selection, OACM5 1.C SC1. Additionally, in vitro experiments were performed to better understand the functional characteristics in relationship with in vivo growth behavior.
OE33 showed successful orthotopic xenografts in $63.6 \%$ $(n=12)$ of the cases. Nevertheless, the volumes remained stable during follow-up, as noted on the serial MRI scans. Subcutaneous tumor take was higher $\left(\mathrm{TT}_{\mathrm{sc}}=100 \%, \mathrm{n}=7\right)$, but resulted in similar small tumor nodules with stable to decreasing volumes. To the best of our knowledge, only one previous study used OE33 cells for orthotopic use. The study was diagnostic and had similar results to ours. Small tumors of 2-3 $\mathrm{mm}$ in diameter at 4 weeks after injection $(\mathrm{n}=5)$ were observed (9). OE33 seems to be a low aggressive cell line with a high subcutaneous and orthotopic tumor take in nude mice, but extremely slow growth pattern. The decreasing subcutaneous volumes may be explained by clearance of Matrigel with slow replacement of tumor cells.

In contrast to the OE33 cell line, OACM5 1.C cells were not able to develop orthotopic tumor nodules $\left(\mathrm{TT}_{\text {orth }}=0 \%, \mathrm{n}=6\right)$. In addition, subcutaneous tumor take was low $\left(\mathrm{TT}_{\mathrm{sc}}=50 \%, \mathrm{n}=8\right)$. To improve these poor tumor take rates, a technique of in vivo selection of tumor cells was applied. As such, the new cell line OACM5 1.C SC1 was established, and successfully led to a significant higher subcutaneous tumor take than the parental cell line [100\% ( $\mathrm{n}=10)$ vs. $50 \%(\mathrm{n}=8) ; \mathrm{P}<0.023]$. Orthotopic tumor take did not significantly differ $[33.3 \%(\mathrm{n}=6)$ vs. $0 \%$ $(\mathrm{n}=6) ; \mathrm{P}=0.467]$. Cell lines had similar in vitro characteristics, except for the significant increased ability of the in vivo selected cell line to form colonies $(\mathrm{P}<0.0001)$. The latter may partially explain the increased tumor take rate.

Another correlation between the in vitro and in vivo results was seen in the invasiveness of the cell lines. The investigated EAC cell lines were almost non-invasive in collagen type I gels in vitro and none of the xenografts in the mouse experiments invaded the surrounding tissues.
A

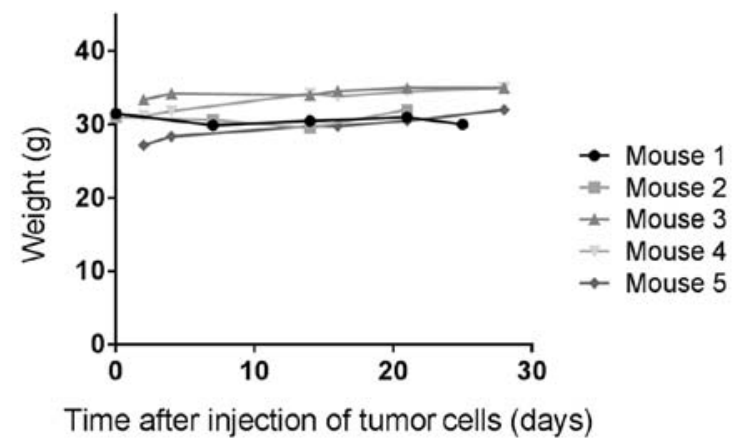

B

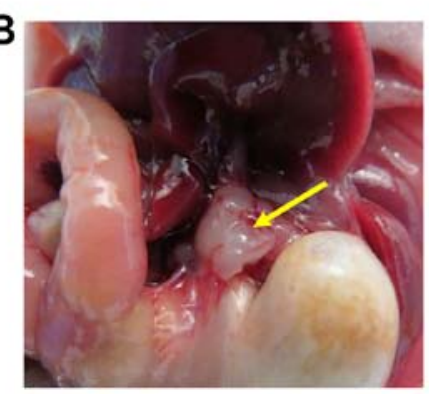

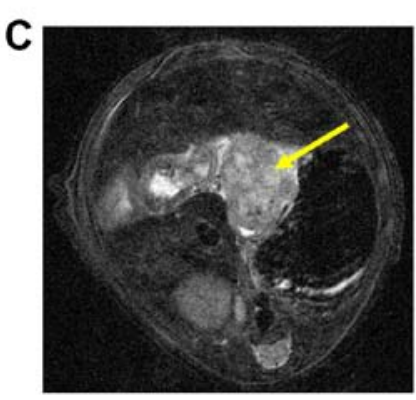

D
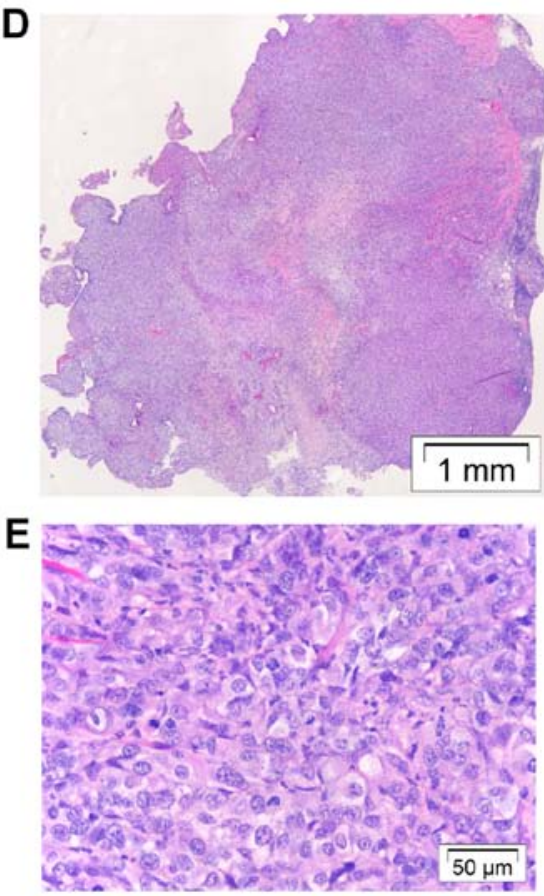

Figure 11. SK-OV-3 Luc IP1 heterotopic esophageal tumor growth. (A) Weight of mice with heterotopic SK-OV-3 Luc IP1 cells at the esophagus. (B) Macroscopic xenograft tumor (yellow arrow) on the distal esophageal wall, with no sign of compression or dilatation of the proximal esophagus. (C) T2-weighed MRI; yellow arrow indicates the voluminous tumor. (D and E) Hematoxylin and eosin (H\&E) staining at different magnifications of a xenograft ovarian tumor at the esophageal wall. 
In addition to in vivo selection, improved tumor take rates may be achieved by simply increasing the amount of injected tumor cells. Unfortunately, the injection volume in the esophageal wall is limited. As such, the amount of injectable tumor cells is also limited to $\sim 1.5 \times 10^{6}$ cells/injection. This can be bypassed by transplanting a subcutaneous tumor fragment on the esophageal wall according to the technique of Gros et al (10). An additional experiment was performed with transplantation of $1 \mathrm{~mm}^{3}$ tumor fragments of a subcutaneous OE33 tumor on the esophageal wall of 7 mice. Due to postoperative complications, 3 animals died within the first week postoperative. The remaining 4 did not show any vital tumor on the esophageal wall up to 70 days of follow up. We believe this is a technically more difficult procedure, with a low success rate when fragments of slow growing tumor nodules are used and we conclude that this is not beneficial for the investigated cell lines.

It needs to be mentioned that the development of EAC in this tumor model differs from the situation in patients. While the pathogenesis is not yet fully understood, it is believed that chronic inflammation of the esophageal mucosa can develop dysplasia, and eventually evolves to EAC. As such, gastroesophageal reflux disease (GERD) is one of the major risk factors for developing EAC, besides obesity (1). In literature, several other models have been described, that reflect the clinical situation more closely (4). On one hand, different reflux models have been used: surgical esphagojejunostomy (23) or drinking of caustic substances (24). These reflux models lead to $<50 \%$ cancer development in a time period of 6 months making it unreliable for therapeutic studies (4). On the other hand, the use of genetically engineered mouse models (GEMMs) has been investigated. Transgenic mice with IL-1 $\beta$ overexpression were shown to develop moderate inflammation by 6 months, with a small percentage of mice developing high grade dysplasia or EAC after 20-22 months (24). Best results with GEMMs were obtained in combination with the caustic substance deoxycholate (DCA), where $45 \%$ of mice developed EAC after a long follow-up period of 15 months (24). The technique of injecting tumor cells in the esophageal wall is considered to be the best option available for the development of a relative rapid and reliable orthotopic mouse model.

Surprisingly, the three investigated EAC cell lines grew more efficient subcutaneously than orthotopically. To rule out technical issues with the orthotopic injection method, the technique was checked with a highly aggressive ovarian carcinoma cell line, SK-OV-3 Luc IP1 cells, that is known to be $100 \%$ tumorigenic in Foxn $1^{n u}$ mice, according to previous experiments in our research group (25). Injection of $5 \times 10^{5} \mathrm{SK}-\mathrm{OV}-3$ Luc IP1 cells in the esophageal wall resulted in $100 \%$ tumor take and $100 \%$ exponential tumor growth $(n=5)$, confirmed on IVIS, MRI and histology (Fig. 11). After 4 weeks, exophytic tumors of $\sim 8 \mathrm{~mm}$ diameter were observed. We believe the low orthotopic tumor take rates with the investigated EAC cells is due to a combination of low aggressive cells and the limited amount of injectable cells.

The fact that the OACM5 1.C SC1 experiments are based on cells originating from one tumor nodule, could be a point of discussion. Nevertheless, the in vivo selection technique is a validated technique to improve cell line characteristics [such as metastatic potential or take rates $(25,26)]$. Our aim was not to validate the technique, but to use it to improve tumor take rates and to show it can be of use for esophageal cancer models. The OACM5 1.C SC1 cell line was authenticated by STR assay, was stable through different passages and led to increased tumor take rates. The unsuccessful in vivo selection of OE33 was probably due to the small amount of tumor cells in the excised tumors and the low clonogenic potential of the cells. Repetitions may most probably lead to the same results.

Finally, the follow-up of esophageal tumor growth in mice is challenging (i.e. due to its location). Performing a laparotomy at different time points is easy, fast and does not require specialized tools or knowledge. However, this causes intra-abdominal adhesions, making esophageal exposure more difficult after every laparotomy, and may cause an inflammatory reaction influencing tumor development. MRI imaging was already confirmed to be feasible and accurate for the follow-up of esophageal cancer in mice $(10,17,18)$. In the present study, a dedicated small animal MRI scanner was used, leading to detailed images. Tumor nodules could be defined precisely as hyper-intense nodular structures, at a fixed location, slightly proximal of the gastroesophageal junction. In addition, the volumes of nodules could be measured accurately. However, MRI is not able to differentiate tumor tissue from inflammatory scar tissue or residual Matrigel. If volumes increase, viable tumor cells are plausible. If not, the presence of tumor cells cannot be assured. It would be interesting to transfect the investigated EAC cell lines with luciferase, such as shown by Gros et al (10), to perform in vivo fluorescence imaging in case of stable nodules, and be able to differentiate viable tumor cells from scar tissue and Matrigel.

The present study is of interest for future experiments. Particularly the OE33 cell line is appropriate for orthotopic injection for diagnostic studies on EAC. Yet, various limitations, such as low aggressive cells, slow growth pattern and different etiology in patients should be kept in mind. It must be mentioned that this is the first study to describe the growth behavior of OACM5 1.C in mice. OACM5 1.C had a poor tumor take rate at an orthotopic and ectopic site. The in vivo selected cell line OACM5 1.C SC1 showed higher subcutaneous take rates. The use of a more immunodeficient mouse strain (NOD SCID mice) could improve tumor take and should be considered for future research with these low aggressive cell lines.

In conclusion, little research is available concerning esophageal cancer, particularly the EAC subtype, which is the more prevalent type in the Western world. The present study provides orthotopic and subcutaneous xenograft EAC models in mice, which may hopefully contribute to further preclinical research on EAC.

\section{Acknowledgements}

The authors would like to thank Natacha Rosseel for the assistance with laboratory and animal procedures, and Glenn Wagemans for the assistance with in vitro procedures.

\section{References}

1. Napier KJ, Scheerer M and Misra S: Esophageal cancer: A Review of epidemiology, pathogenesis, staging workup and treatment modalities. World J Gastrointest Oncol 6: 112-120, 2014. 
2. Stahl M, Mariette C, Haustermans K, Cervantes A and Arnold D ESMO Guidelines Working Group: Oesophageal cancer: ESMO Clinical Practice Guidelines for diagnosis, treatment and follow-up. Ann Oncol 24 (Suppl 6): vi51-vi56, 2013.

3. Gavin AT, Francisci S, Foschi R, Donnelly DW, Lemmens V, Brenner $\mathrm{H}$ and Anderson LA; EUROCARE-4 Working Group: Oesophageal cancer survival in Europe: A EUROCARE-4 study. Cancer Epidemiol 36: 505-512, 2012.

4. Tétreault MP: Esophageal cancer: Insights from mouse models. Cancer Growth Metastasis 8 (Suppl 1): S37-S46, 2015.

5. Bibby MC: Orthotopic models of cancer for preclinical drug evaluation: Advantages and disadvantages. Eur J Cancer 40 852-857, 2004.

6. Hanahan D and Weinberg RA: Hallmarks of cancer: The next generation. Cell 144: 646-674, 2011.

7. Kuroda S, Kubota T, Aoyama K, Kikuchi S, Tazawa H, Nishizaki M, Kagawa S and Fujiwara T: Establishment of a non-invasive semi-quantitative bioluminescent imaging method for monitoring of an orthotopic esophageal cancer mouse model. PLoS One 9: e114562, 2014.

8. Song S, Chang D, Cui Y, Hu J, Gong M, Ma K, Ding F, Liu ZH and Wang TY: New orthotopic implantation model of human esophageal squamous cell carcinoma in athymic nude mice. Thorac Cancer 5: 417-424, 2014.

9. Habibollahi P, Figueiredo JL, Heidari P, Dulak AM, Imamura Y, Bass AJ, Ogino S, Chan AT and Mahmood U: Optical imaging with a cathepsin B activated probe for the enhanced detection of esophageal adenocarcinoma by dual channel fluorescent upper GI endoscopy. Theranostics 2: 227-234, 2012.

10. Gros SJ, Dohrmann T, Peldschus K, Schurr PG, Kaifi JT, Kalinina T, Reichelt U, Mann O, Strate TG, Adam G, et al: Complementary use of fluorescence and magnetic resonance imaging of metastatic esophageal cancer in a novel orthotopic mouse model. Int J Cancer 126: 2671-2681, 2010.

11. Drenckhan A, Kurschat N, Dohrmann T, Raabe N, Koenig AM, Reichelt U, Kaifi JT, Izbicki JR and Gros SJ: Effective inhibition of metastases and primary tumor growth with CTCE-9908 in esophageal cancer. J Surg Res 182: 250-256, 2013.

12. Kuroda S, Fujiwara T, Shirakawa Y, Yamasaki Y, Yano S, Uno F, Tazawa H, Hashimoto Y, Watanabe Y, Noma K, et al: Telomerase-dependent oncolytic adenovirus sensitizes human cancer cells to ionizing radiation via inhibition of DNA repair machinery. Cancer Res 70: 9339-9348, 2010.

13. Furihata T, Sakai T, Kawamata H, Omotehara F, Shinagawa Y, Imura J, Ueda Y, Kubota $\mathrm{K}$ and Fujimori T: A new in vivo mode for studying invasion and metastasis of esophageal squamous cell carcinoma. Int J Oncol 19: 903-907, 2001.

14. Ip JC, Ko JM, Yu VZ, Chan KW, Lam AK, Law S, Tong DK and Lung ML. A versatile orthotopic nude mouse model for study of esophageal squamous cell carcinoma. Biomed Res Int 910715, 2015.
15. Ohara T, Takaoka M, Sakurama K, Nagaishi K, Takeda H, Shirakawa Y, Yamatsuji T, Nagasaka T, Matsuoka J, Tanaka N, et al: The establishment of a new mouse model with orthotopic esophageal cancer showing the esophageal stricture. Cancer Lett 293: 207-212, 2010.

16. Hori T, Yamashita Y, Ohira M, Matsumura Y, Muguruma K and Hirakawa K: A novel orthotopic implantation model of human esophageal carcinoma in nude rats: $\mathrm{CD} 44 \mathrm{H}$ mediates cancer cell invasion in vitro and in vivo. Int J Cancer 92: 489-496, 2001.

17. Gros SJ, Kurschat N, Drenckhan A, Dohrmann T, Forberich E, Effenberger K, Reichelt U, Hoffman RM, Pantel K, Kaifi JT, et al: Involvement of CXCR4 chemokine receptor in metastastic HER2-positive esophageal cancer. PLoS One 7: e47287, 2012.

18. Gros SJ, Kurschat N, Dohrmann T, Reichelt U, Dancau AM, Peldschus K, Adam G, Hoffman RM, Izbicki JR and Kaifi JT: Effective therapeutic targeting of the overexpressed HER-2 receptor in a highly metastatic orthotopic model of esophageal carcinoma. Mol Cancer Ther 9: 2037-2045, 2010.

19. Gros SJ, Dohrmann T, Rawnaq T, Kurschat N, Bouvet M, Wessels J, Hoffmann RM, Izbicki JR and Kaifi JT: Orthotopic fluorescent peritoneal carcinomatosis model of esophageal cancer. Anticancer Res 30: 3933-3938, 2010.

20. Castro C, Bosetti C, Malvezzi M, Bertuccio P, Levi F, Negri E, La Vecchia C and Lunet N: Patterns and trends in esophageal cancer mortality and incidence in Europe (1980-2011) and predictions to 2015. Ann Oncol 25: 283-290, 2014.

21. Almhanna K, Meredith KL, Hoffe SE, Shridhar R and Coppola D: Targeting the human epidermal growth factor receptor 2 in esophageal cancer. Cancer Control 20: 111-116, 2013.

22. De Wever O, Hendrix A, De Boeck A, Westbroek W, Braems G Emami S, Sabbah M, Gespach C and Bracke M: Modeling and quantification of cancer cell invasion through collagen type I matrices. Int J Dev Biol 54: 887-896, 2010.

23. Raggi M, Langer R, Feith M, Friess H, Schauer M and Theisen J: Successful evaluation of a new animal model using mice for esophageal adenocarcinoma. Langenbecks Arch Surg 395: 347-350, 2010.

24. Quante M, Bhagat G, Abrams JA, Marache F, Good P, Lee MD, Lee Y, Friedman R, Asfaha S, Dubeykovskaya Z, et al: Bile acid and inflammation activate gastric cardia stem cells in a mouse model of Barrett-like metaplasia. Cancer Cell 21: 36-51, 2012.

25. De Vlieghere E, Carlier C, Ceelen W, Bracke M and De Wever O: Data on in vivo selection of SK-OV-3 Luc ovarian cancer cells and intraperitoneal tumor formation with low inoculation numbers. Data Brief 6: 542-549, 2016.

26. Minn AJ, Gupta GP, Siegel PM, Bos PD, Shu W, Giri DD, Viale A, Olshen AB, Gerald WL and Massagué J: Genes that mediate breast cancer metastasis to lung. Nature 436: 518-524, 2005. 